\title{
„Wir haben unseren Mitgliedern einiges zu bieten"
}

\author{
Entgegen dem allgemeinen Trend eines Mitgliederschwundes in Vereinen und Verbänden stei- \\ gen die Mitgliederzahlen im FVDZ jährlich um 2,5 bis drei Prozent an. Warum das so ist, erklärt \\ Dirk René Ruffing, der im Bundesvorstand das Ressort Mitgliedermanagement verantwortet.
}

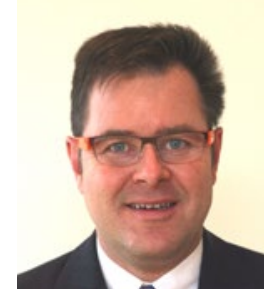

\section{Wo stand der Verband, als Sie den Bereich Mitgliedermanagement übernommen haben?}

Ich hatte das große Glück, das frühere Ressort der heutigen Bundesvorsitzenden zu übernehmen, die sehr viele Ideen in diesem Bereich in den Verband und auf den Weg brachte. Kerstin Blaschke hatte für das Mitgliedermanagement bereits eine Struktur geschaffen, und die Talsohle der Mitgliederzahlen, in die der Verband nach den Bremer Beschlüssen und der darauffolgenden Lethargie gerauscht war, war bereits überwunden. Ich habe ein aufgeräumtes Konzept vorgefunden, auf dem ich aufbauen konnte.

\section{Was haben Sie in der zurückliegenden Legislaturperiode erreicht?}

Ich habe beispielsweise zwei Studenten-/HochschulreferentenWorkshops in Berlin durchgeführt.

Diese sind eine hervorragende Gelegenheit, sich zwischen den Landesverbänden in der Nachwuchsarbeit auszutauschen. Und es gab Arbeitsgespräche in der Bundesgeschäftsstelle, vor allem zu Beginn meiner Arbeit. Ich musste ja die Strukturen im Verband kennenlernen.

Jeweils im Frühjahr habe ich zu Treffen der AG Mitglieder eingeladen, bei denen der Fahrplan für das laufende Jahr besprochen wurde, wo die Reise in Sachen Mitgliedermanagement hingehen soll. Zur Weiterentwicklung von MEDI-Learn für Zahnmediziner gab es ein Treffen mit der Deutschen Ärzteversicherung. Und es gab Treffen mit Studenten, beispielsweise in Göttingen, in Homburg, in Köln auf der IDS oder auf Usedom. Denn nur, wer sein Ohr an der Zielgruppe dran hat, kann bedarfsgerechte Aktionen entwickeln.

Wir können vorweisen, dass - entgegen dem allgemeinen Trend zum Mitgliederschwund in Vereinen und Verbänden - durch große Anstrengung und permanentes Fördern des Nachwuchses und nicht zuletzt auch durch den neuen Wind, der durch den Verband seit der Wahl des aktuellen Bundesvorstandes weht, die Mitgliederzahlen beständig zwischen 2,5 und drei Prozent pro Jahr steigen. Der Verband zählt heute wieder 19.000 Mitglieder.

\section{Was ist das Ziel für die nächste Legislaturperiode?}

Ich möchte keine Leuchtturm-Projekte starten, die einen kurzfristig aufhorchen lassen oder der Selbstbeweihräucherung dienen, sondern das Mitgliedermanagement auf eine solide Basis stellen. Wir arbeiten beständig an einem Mehrwert der Verbandsmitgliedschaft. Mit FVDZ Ökonomie - zu nennen sind da fibu-doc, das Steuerberaternetzwerk, die Rechtsberatung der FVDZ Akademie, mit den Kongressen und mit MEDILearn, dem Mentoring-Programm und unserer Hochschularbeit haben wir da einiges zu bieten. Die Mitgliedschaft im Verband muss sich auch wirtschaftlich für die Mitglieder auszahlen. Darüber hinaus bieten wir gebündeltes Wissen und Informationen und nicht zuletzt eine starke Gemeinschaft.

Dieser Gedanke zählt vor allem zu meinen weiteren Zielen: die Gemeinschaft im Verband zu stärken, den FVDZ als positive Marke zu positionieren. Wir haben ja schon beinahe alles im Verband, wir müssen es nur noch besser zu zielgruppengerechten Paketen schnüren und optimal kommunizieren.

Wir werden in diesem Sinne bedarfsgerechte Bausteine anbieten, um insbesondere die neue, nachwachsende Generation an den Verband zu binden.

Wir werden ein spezifisches Programm präsentieren: vom Studenten auf dem Weg zum Vorbereitungsassistenten und vom Assistenten auf dem Weg in die Niederlassung, denn die Freiberuflichkeit steht ganz oben auf unserer Agenda

Und nicht zuletzt schwebt mir ein Treffen der Generationen vor, mit dem ich gerne das Gemeinschaftsgefühl und die Marke FVDZ für alle Mitglieder stärken möchte.

Das beste Mitgliedermanagement ist in meinen Augen ein fortwährendes Einbinden, der persönliche Kontakt, hier vor allem über die Landesverbände, Vertrauen schaffen in den Verband. „Wer Vertrauen gibt, nimmt Zukunft vorweg.“ Dieser Satz von dem deutschen Soziologen Niklas Luhmann muss die Basis unseres Handelns sein.

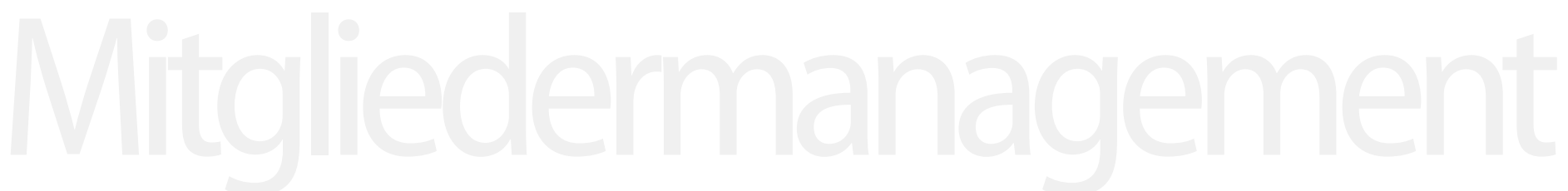

